\title{
O Sanatório São Julião na mídia impressa campo-grandense (1941-1970): um estudo historiográfico
}

Sanatório São Julião in the press media of Campo Grande (1941-1970): a historical study

El Sanatório São Julião en los medios impresos de Campo Grande (1941-1970): un estudio historiográfico

Kely Cristina Garcia Vilena ${ }^{1}$ Rodrigo Lopes Miranda²

${ }^{1}$ Doutoranda e mestre em Psicologia pela Universidade Católica Dom Bosco (UCDB). Docente no curso de Graduação em Enfermagem da UCDB. E-mail: kelyvilhena@yahoo.com.br, Orcid: http://orcid.org/0000-0003-2276-6165

${ }^{2}$ Doutor em Educação pela Universidade Federal de Minas Gerais (UFMG). Docente e pesquisador no Programa de Pós-Graduação - Mestrado e Doutorado em Psicologia da Universidade Católica Dom Bosco (UCDB). E-mail: rlmiranda@ucdb.br, Orcid: http://orcid.org/0000-0003-3222-7368 
Resumo: O objetivo deste trabalho é apresentar e discutir a forma como o Sanatório São Julião circulou na mídia impressa campo-grandense, entre 1941 e 1970. Estima-se analisar, por meio do discurso midiático, práticas de assistência ao Sanatório e aos seus internos, por parte da sociedade. As fontes primárias utilizadas foram notícias publicadas em jornais, disponíveis no Arquivo Municipal de Campo Grande (ARCA), a saber: Correio do Estado, 0 Matogrossense e o Jornal do Comércio. As análises do material sugerem que a sociedade campo-grandense, movida por certa visão social da lepra, manifestada pela mídia impressa, "amparou" os internados no Sanatório São Julião com doações de diversos gêneros, desde alimentos a expressivos valores, efetuados por "generosos" campo-grandenses. Assim, as imagens evocadas pelo discurso midiático, referentes ao Sanatório São Julião, concebem a ideia de um cuidado em saúde ligado a práticas assistencialistas.

Palavras-chave: história da saúde; lepra; políticas de saúde; políticas públicas.

\begin{abstract}
This investigation aims to present and to discuss how the Sanatório São Julião circulated in the press media of Campo Grande, between 1941 and 1970. More specifically, it analyzes practices of assistance to the Sanatório and its internees by society through news published by some newspapers, e.g., Correio do Estado, O Matogrossense and Jornal do Comércio. The analyzes of primary sources suggest that Campo Grande society, driven by certain social images of Leprosy in the print media, supported the inmates at the Sanatório São Julião with donations of diverse genres, from foods to high values, made by "generous" people. Therefore, the images evoked by the media the idea of health care linked to welfare practices to São Julião's internees.
\end{abstract}

Keywords: history of health; leprosy; health policies; public policies.

Resumen: El objetivo de este trabajo es presentar y discutir la forma como el Sanatorio São Julião circuló en los medios impresos de Campo Grande, entre 1941 y 1970. Se estima analizar, por medio del discurso mediático, prácticas de asistencia al Sanatorio y a sus internos, por parte de la sociedad. Las fuentes primarias utilizadas fueron noticias publicadas en periódicos disponibles en el Archivo Municipal de Campo Grande (ARCA), tales como: Correio do Estado, O Matogrossense y el Jornal do Comercio. Los análisis del material sugieren que la sociedad de Campo Grande, movida por cierta visión social de la lepra, en los medios impresos, "amparó" a los internados en el Sanatorio São Julião con donaciones de diversos géneros, desde alimentos a valores altos, hechos por "generosas" personas de la ciudad. Así, las imágenes evocadas por el discurso mediático, referentes al Sanatorio São Julião, conciben la idea de un cuidado en salud conectado a las prácticas asistenciales.

Palabras clave: historia de la salud; lepra; políticas de salud; políticas públicas. 


\section{INTRODUÇÃO}

De acordo com o Ministério da Saúde, a hanseníase é uma doença crônica, infectocontagiosa, cujo agente etiológico é o Mycobacterium leprae. Devido a sua magnitude e alto poder incapacitante, é meta da Organização Pan-Americana de Saúde (OPAS) e da Organização Mundial da Saúde (OMS) a eliminação da doença, classificando-a como um problema de saúde pública. Para isso, desde 1986, foram apresentadas estratégias para erradicação da hanseníase ou, pelo menos, drástica redução no número de casos, até o ano 2000. Nesse contexto, o Brasil, assim como outros países, implementou políticas de tratamento, campanhas e diretrizes para o controle da doença. No começo de 2005, a eliminação da hanseníase havia sido alcançada em quase todos os países, mas o Brasil era uma das exceções e, assim, concordou em se empenhar no controle da doença, usando o impacto político da campanha global pela sua eliminação, com um prazo estendido até o ano de 2010. Entretanto, em 2016, foram notificados 25.218 casos novos, perfazendo uma taxa de detecção de 12,2/100 mil habitantes. Tais parâmetros classificam o país como sendo de alta carga para a doença. Nesse sentido, apesar dos esforços de todas as esferas do governo brasileiro, o objetivo da erradicação da hanseníase no país não foi alcançado e segue com novo prazo, até 2020. As recomendações da Estratégia Global para Hanseníase 2016-2020, da OMS, têm como principal objetivo reduzir a carga da doença. A estratégia pauta-se em três grandes pilares: o fortalecimento do controle e da parceria governamental, o combate da hanseníase e suas complicações e o enfrentamento da discriminação com promoção da inclusão social. Estes pilares abrangem a deteç̧ão precoce de casos, o tratamento imediato com esquema de poliquimioterapia (PQT), o desenvolvimento de pesquisas básicas e o enfrentamento do estigma, promovendo a mobilização e a sensibilização junto à comunidade. O Brasil está em consonância com tais recomendações. No entanto, de acordo com a OMS, o país encontra-se na lista daqueles que tratam a doença de forma ineficiente, e os números de novos casos registrados são um sinal de que o problema está longe de ser controlado.

Diante desse contexto, contemporaneamente, um conjunto de debates tem ocorrido sobre os motivos pelos quais o Brasil não consegue 
eliminar a hanseníase e, nesse cenário, parece-nos que dois argumentos se destacam. O primeiro diz respeito ao preconceito e à falta de informação sobre a doença, o que, ao longo do tempo, atrapalha a sua erradicação. 0 fato tenderia para a direção de se investir em campanhas que alertem as pessoas para o problema e que contribuam para eliminar o preconceito em torno da doença. O segundo argumento alega que só seria possível a erradicação da hanseníase reduzindo-se a pobreza e melhorando a qualidade de vida da população. Assim, um dos desafios para o controle da doença seria a desigualdade social no Brasil. Tal argumento tem relação direta com dados estatísticos exibidos no país, no período de 2012 a 2016, indicando que locais de pobreza e miséria apresentam maior incidência da doença, como, por exemplo, as regiões Centro-Oeste e Norte.

Complementar a essa mirada contemporânea, é possível uma análise historiográfica em que se observa a profilaxia e a erradicação da doença a partir de, pelo menos, dois cenários. Por um lado, a forma como o Estado prioriza as ações de combate à hanseníase tem relação direta com o grau de importância que a saúde ocupa no cenário nacional. Por outro, as imagens que circulam na mídia, correlacionadas ao tema da hanseníase, contribuem diretamente com a forma como a sociedade lida - ou deixa de lidar - com o fato. Nesse sentido, o artigo se propõe a apresentar a forma como o Sanatório São Julião circulou na mídia impressa campo-grandense entre 1941 e 1970, período em que se manteve sob a administração do Estado, bem como tais representações se atualizam, no presente, fomentando reflexões sobre as estratégias atuais no combate à hanseníase. Visando ao objetivo proposto, o texto está dividido em três seções. Primeiramente, faz-se uma descrição sobre as primeiras estratégias de assistência aos portadores da lepra no Brasil. Na sequência, abordam-se circunstâncias socioeconômicas que culminaram na construção do Sanatório São Julião em Campo Grande. Por fim, apresenta-se uma análise e uma discussão sobre a imagem do Sanatório São Julião e da incidência e tratamento da lepra, pela mídia impressa campo-grandense, entre 1941 e 1970. Logo, estimamos apresentar que as imagens evocadas pelo discurso midiático, referentes ao Sanatório São Julião, concebem a ideia de um cuidado em saúde ligado a práticas assistencialistas. 


\section{MÉTODO}

Trata-se de uma pesquisa historiográfica e, portanto, sedimentada em uma abordagem qualitativa de pesquisa. A seleção das fontes primárias ocorreu no Arquivo Municipal de Campo Grande (ARCA) e obedeceu ao seguinte critério: seleção de notícias publicadas em jornais ali arquivados, no período de 1941 a 1970, que, em seu título, fizessem referência ao Sanatório São Julião. O recorte temporal foi selecionado por compreender o período em que a instituição esteve sob a administração do governo do Estado de Mato Grosso (MT) $)^{1}$. Assim, ao final, foram selecionadas quatro notícias publicadas em jornais, a saber: Correio do Estado, O Matogrossense e o Jornal do Comércio. Para análise dos resultados, utilizaram-se os conceitos da Memória Social (SÁ, 2007) e os fundamentos da Análise Documental (LE GOFF, 1990).

A estratégia metodológica do uso de periódicos e jornais tem se mostrado uma importante fonte de pesquisa em diferentes disciplinas ligadas à área da saúde - e.g., Psicologia (LIMA; OLIVEIRA, 2015) e Enfermagem (ESPÍRITO SANTO; OGUISSO; FONSECA, 2011) -, assim como na História (ALVES, 2012; LAPUENTE, 2015). Esse tipo de mídia pode ser considerado como uma expressão da cultura impressa de um grupo social, portanto constitui produtos comunicativos que permitem observar, ao longo do tempo, os elementos pertencentes a um determinado grupo social (BATISTA; MACHADO; GERKEN, 2015; CARA et al., 2018). No caso específico do regime de historicidade analisado, a primeira metade do século XX, vale refletir que o jornal auxiliava a definir sobre o que a maioria das pessoas conversavam e o que elas pensavam sobre determinados fatos. Assim, a mídia impressa impactava não só o que seria discutido, mas como e por quem. Nesse sentido, interessam a este estudo questões de agendamento, inserção e hierarquização de conteúdo, como aquelas discutidas pela hipótese do agenda-setting (HOHLFELDT, 1997; WOLF, 2005). Segundo "essa hipótese,

\footnotetext{
${ }^{1}$ O Estado de Mato Grosso, localizado na região Centro-Oeste, foi dividido em 1977, tornando-se a sua região norte em Estado de Mato Grosso, com a capital Cuiabá, e a região sul, em Mato Grosso do Sul (MS), com a capital Campo Grande (CAMPESTRINI, GUIMARÃES, 1991).
} 
a mídia, pela seleção, disposição e incidência de seus produtos, determina os temas sobre os quais o público falará e discutirá" (BARROS FILHO, 2005, p. 157). Ou seja: a imprensa pode até não decidir como se deve pensar, mas protagoniza a distribuição dos assuntos da ordem do dia.

\section{RESULTADOS E DISCUSSÃO}

\subsection{Contexto social para a assistência à lepra no Brasil}

Desde o período colonial, a lepra já era conhecida no Brasil, porém não era classificada como um problema de saúde pública, e sim como um aspecto característico da população (LEANDRO, 2009). A doença passou a figurar, no país, como um grave problema de saúde pública, a partir da década de 1910, pois ameaçava a população sadia e, como tal, a sociedade estava a pedir respostas do governo, uma vez que as ações de profilaxia e tratamento da doença, até aquele momento, eram realizadas, em grande parte, por instituições religiosas e beneficentes (OPROMOLLA; LAURENTI, 2011). Embora o discurso daquelas autoridades apontasse para um aumento da incidência da doença, no início do século XX, tornando-a mais visível, tal questão estava incluída em um contexto mais amplo, envolvendo a posição da saúde no cenário brasileiro, que ganhava amplitude com a nova configuração política inaugurada com a República, pautada nos ideais de ordem, progresso e civilização, i.e., a ideia de transformar o país em "civilização", em uma situação diversa daquela de barbárie na qual se encontrava (CASTRO, 2005; MACIEL, 2007). Desse modo, o projeto modernizador do governo brasileiro e a modificação na compreensão do processo saúde/ doença colocaram em evidência um problema nacional, no qual nada havia de novo, como as doenças endêmicas e as epidemias rurais. Diante disso, necessitava-se, além de outros aspectos, de melhorar as condições sanitárias das áreas consideradas vitais para a economia nacional, pois se acreditava que a incidência das doenças estava intimamente relacionada à pobreza brasileira (CASTRO SANTOS; FARIA; MENEZES, 2008).

Todavia a preocupação central com a saúde não se traduzia, necessariamente, pela questão do direito social ou da dignidade humana. Tal motivação estava associada aos interesses econômicos das elites em man- 
ter o trabalhador sadio, para que mantivesse suas funções produtivas, em defesa do projeto de modernização do país. Nesse sentido, a medicina se colocou no papel de guia do Estado para assuntos sanitários e se comprometia a garantir a melhoria da saúde individual e coletiva, considerando-se como a panaceia de um país atrasado, no qual predominava um tipo social representado pela figura ontológica do Jeca Tatu, criado por Monteiro Lobato, estereótipo do homem do campo necessitado de cuidados, cujas enfermidades o impediam de participar do esforço de fazer o Brasil progredir (BERTOLLI FILHO, 2004). Assim, diversas doenças passaram a receber a atenção especial do governo, e.g., a lepra, a varíola, a difteria, a febre tifoide e a tuberculose, que ganharam uma inspetoria própria, por meio do Decreto n. 4.464, de 12 de julho de 1902. O decreto se adequava ao modelo de saúde coletiva higienista-preventiva que havia se instalado no país e tinha por finalidade estabelecer a atuação dos inspetores sanitários, no sentido de identificar locais que pudessem ser focos de doenças, bem como a notificação obrigatória daquelas doenças infectocontagiosas. As medidas profiláticas desse modelo de saúde consistiam, entre outras questões, na vacinação de alguns casos de doenças para as quais havia vacina, ou por meio do tratamento daquelas doenças para as quais ainda não havia vacina. No caso das doenças infectocontagiosas que não contavam com vacina nem tratamento, como no caso da lepra, as medidas para conter a propagação resumiam-se em isolar o doente, a fim de evitar a sua disseminação entre os indivíduos sãos (SILVA, 2015).

Nesse contexto, dois grupos discutiam práticas terapêuticas a serem implementadas na profilaxia da lepra. O primeiro deles, os contagionistas, enfatizava o isolamento pela intervenção do Estado. O segundo grupo empenhava-se pela melhoria das condições de higiene e alimentação dos doentes, defendendo, portanto, uma intervenção no meio, nas relações e no espaço social. Contudo, no Brasil, as discussões das políticas isolacionistas cogitaram a construção de hospitais-colônia em ilhas próximas a Manaus. Sendo suficientemente distantes, sua localização dificultaria o acesso aos doentes, inibiria fugas e, assim, evitaria o contato com a população saudável (COSTA, 2007; MACIEL, 2007). Todavia a execução do isolamento em ilhas mostrou-se inviável. Além disso, a partir da década de 1910, a lepra 
se transformara em um grave problema de saúde pública para o Estado. Diferentes discursos no Brasil passaram, então, a indicar o isolamento como necessário. A questão era apenas definir o tipo de isolamento que seria adotado, porquanto havia uma divergência entre, pelo menos, dois grupos que apoiavam o isolamento compulsório no país: os humanísticos e os isolacionistas. Ambos os grupos defendiam a política do isolamento, porém os humanísticos defendiam uma política de internação mais "humanitária", com internações domiciliares e construção de hospitais-colônia para a internação de, apenas, casos excepcionais. Por sua vez, os isolacionistas, grupo majoritário, composto prioritariamente por políticos, defendiam a construção de hospitais-colônia em cada estado do país e a internação compulsória, em massa, de todos os doentes (COSTA, 2007; SANTOS, 2011).

As discussões acerca da lepra tiveram fim com "a definição das colônias agrícolas como sendo o modelo para o isolamento de leprosos, que permitia a manutenção da vida social e o resguardo da população sadia" (SILVA, 2015, p. 44). Diante disso, em 1923, criou-se a Inspetoria de Profilaxia da Lepra, com a promulgação do Decreto n. 16.300, de 31 de dezembro de 1923, que estabelecia medidas de políticas públicas, no sentido de difundir o controle da doença. O decreto tinha, como estratégia primordial, conter a propagação da doença por meio da segregação compulsória dos doentes. 0 regulamento previa a notificação obrigatória de casos suspeitos da doença, bem como o levantamento do censo de leprosos e seu isolamento obrigatório em domicílio, colônias agrícolas, sanatórios, hospitais ou asilos, entre outras medidas. Um dos primeiros estados a seguir as recomendações sanitárias estabelecidas foi o Estado de São Paulo (SP), com a construção de um hospital-colônia que serviria como modelo para os demais estados do país (CASTRO SANTOS; FARIA; MENEZES, 2008). Apesar disso, com a República das Oligarquias, modelo político que configurava, naquele momento, no país, vários estados deixaram de seguir tais recomendações. A prática do isolamento compulsório só foi totalmente implementada na década de 1930, quando Getúlio Vargas assumiu a presidência da República. Usando um discurso modernizante, ele centralizou o poder do Estado e passou a investir em políticas de Estado, e.g., saúde e educação, criando o Ministério da Educação e Saúde, em novembro de 1930 (BERTOLLI FILHO, 2004). Com 
essas medidas e por meio de estratégias políticas, o governo federal passou a se consolidar como poder público e se tornou missão do Estado segregar os leprosos. Na prática, o governo solicitou um estudo para investigar o quantitativo de leprosos que existiam no país e, de acordo com o estudo, foi calculada a quantidade de leprosários necessários para a segregação, em massa, dos doentes (SANTOS, 2003). Com isso, houve a reforma e a construção de hospitais-colônia em regiões consideradas endêmicas, por todo o país. Assim, a hegemonia da política isolacionista prevaleceu e a internação compulsória foi, finalmente, colocada em prática (CUNHA, 2010).

\subsection{O Sanatório São Julião e o isolamento compulsório em Campo Grande}

Até o ano de 1940, Mato Grosso contava com um único leprosário, denominado Hospital de São João dos Lázaros, destinado à reclusão dos leprosos de todo o Estado, localizado ao norte, na cidade de Cuiabá. Em 1941, porém, foi construído outro hospital-colônia, denominado Sanatório São Julião, na cidade de Campo Grande, localizada ao sul do Estado, com a finalidade de abrigar os doentes da região Centro-Oeste: "um novo e moderno hospital de isolamento que a partir daquele ano receberia os leprosos de todo o estado" (NASCIMENTO, 2001, p. 51). Além disso, o novo hospital receberia aqueles que já se encontravam isolados no Hospital de São João dos Lázaros, instalado ao norte do Estado e que seria desativado, a partir de então. Tais escolhas revelavam uma relação direta com o processo de modernização do país, como também com o processo de desenvolvimento local.

Historicamente, havia diferenças entre o norte e o sul de Mato Grosso. O norte ocupava mais de dois terços do território estadual e se desenvolveu pela extração do ouro, da garimpagem do diamante e da extração da borracha. O sul ocupava menos de um terço e, praticamente separado pela planície do pantanal, desenvolveu-se por meio da criação de gado, da exploração da erva-mate e da agricultura (CAMPESTRINI; GUIMARÃES, 1991). Parece que, embora participasse com mais de dois terços da arrecadação estadual, o sul do Estado não recebia a contrapartida em investimentos de que necessitava para o seu desenvolvimento. Tais diferenças geográficas, 
históricas, administrativas e culturais teriam levado a reivindicações de divisão do Estado a partir da década de 1930, o que ocorreu em 1977, por meio da Lei Complementar n. 31, de 11 de outubro de 1977. Até a divisão, Cuiabá era a capital do Estado e, com a divisão, Campo Grande passou a ser a capital de Mato Grosso do Sul (MS).

Campo Grande teve seu processo de desenvolvimento e modernização favorecido com a inauguração da Estrada de Ferro Noroeste do Brasil (NOB), em 1914. O processo influenciou na transformação da vila em cidade, em 1918 (CAMPESTRINI; GUIMARÃES, 1991). Até então, Campo Grande já havia se tornado ponto de referência comercial entre fazendeiros, mascates e outros comerciantes, já que se localizava em um ponto estratégico de trânsito entre várias cidades comerciais, como Corumbá, situada mais ao sul de Mato Grosso, por onde entravam as importações provenientes de Porto Esperança, na Bolívia, e Bauru, SP, local de acesso ao porto de Santos. A construção da NOB, ligando Corumbá-Campo Grande-Bauru, facilitou ainda mais o comércio, pois a locomotiva diminuía o tempo de viagem dos comerciantes (COSTA, 1999). Assim, a capital do Estado, Cuiabá, localizada ao norte - centro hegemônico das relações econômicas do Estado, até então -, dava lugar a Campo Grande, geograficamente localizada ao sul do Estado. Nesse sentido, o processo de escolha do novo local para segregação dos doentes da região Centro-Oeste parece ter relação direta com tais questões políticas e econômicas, ligadas ao processo de modernização do país, bem como ao desenvolvimento e à modernização do Estado, especificamente pela posição geográfica em que Campo Grande se encontrava (VILENA, 2018).

Seguindo as recomendações do projeto para a construção dos hospitais-colônia, ou colônias agrícolas, estabelecido pelo Decreto n. 16.300, de 31 de dezembro de 1923, o Sanatório São Julião foi inaugurado em Campo Grande, em 5 de agosto de 1941. O local onde o hospital-colônia foi construído era um ambiente rural, afastado da cidade: ficava a $14 \mathrm{~km}$ de Campo Grande, ao norte, na rodovia BR-163 (GALVÃO, 1999). O objetivo de tal escolha visava a uma adequação ao que preconizava o regulamento sanitário, i. e., os hospitais-colônia deveriam seguir o modelo de uma pequena cidade, com "laboratórios, biblioteca, posto de saúde, necrotério, 
refeitório e habitações para internos e funcionários" (SANTOS, 2011, p. 255). Deveriam, outrossim, ser autossustentáveis economicamente, de modo que a instituição pudesse abrigar internos ocupando cargos e contribuindo para o seu funcionamento, permitindo que eles continuassem com as atividades que executavam antes da internação, sendo produtivos, autossuficientes, mantendo a sua vida social e, ao mesmo tempo, o resguardo da população sadia (CASTRO SANTOS; FARIA; MENEZES, 2008; SILVA, 2015).

Entre as décadas de 1941 e 1970, ocorreram dois eventos, um em âmbito nacional e outro em âmbito local. No contexto nacional, na década de 1960, produziu-se o Decreto n. 968, de maio de 1962, que determinava o fim do isolamento compulsório, visto que terapêuticas alternativas a isso estavam sendo colocadas em prática. As terapêuticas, entretanto, não curavam a doença, embora contribuíssem para que o doente deixasse de transmitir o bacilo. Nesse sentido, no âmbito da praticidade, os doentes permaneceram internados, porém não mais compulsoriamente (CANIATO, 2013). Localmente, na década de 1970, o governo estadual deixou de administrar o Sanatório São Julião e passou a sua administração para a Associação de Auxílio e Recuperação dos Hansenianos (AARH), de Campo Grande, por meio do Decreto n. 1.364, de 20 de novembro de 1970. Tratava-se de uma instituição filantrópica, de iniciativa privada, criada na década de 1970, com a finalidade de assumir, administrativamente, o Sanatório São Julião.

\subsection{O Sanatório São Julião na Mídia Campo-Grandense}

Com o estabelecimento do isolamento compulsório, o Estado firmava compromisso no sentido de zelar pelo bem-estar da população contaminada com a lepra e anunciava, por meio de propagandas, que os hospitais-colônia eram os estabelecimentos indicados para o doente internar-se, adquirir assistência médica adequada e cura para a enfermidade (OPROMOLLA; LAURENTI, 2011; SANTOS, 2011). Assim, como preconizava o Regulamento Sanitário de 1923:

As colônias agrícolas, sempre preferíveis, deverão ter bastante amplitude para nelas se poder estabelecer uma verdadeira vila de leprosos, e, além das condições que assegurem do melhor modo os seus fins, 
deverão ter hospitais para os que necessitarem cura de doenças e afecções intercorrentes, creche, orfanato e asilo para os incapazes. [...] serão de preferência enviados, além dos que o desejarem, os que forem ainda capazes de pequenos trabalhos, regulados segundo prescrição médica. A instalação de estabelecimentos destinados a leprosos obedecerá às condições de conforto e aprazibilidade para os doentes e de proteção para as populações vizinhas [...] os doentes manterão rigoroso asseio corporal e os portadores de lesões abertas deverão tê-las sempre tratadas e oclusas. (BRASIL, 1923, p.32-3).

Além das promessas de propiciar atendimento e ambiente adequado aos internados, o Estado se comprometia em ajudar, pelo menos temporariamente, as famílias que tivessem o seu chefe internado compulsoriamente, desde que houvesse escassez de recursos para a manutenção dos familiares, como se lê nos artigos 154 e 155, do Regulamento Sanitário de 1923:

Art. 154. O isolamento do leproso, tratando-se do chefe da família ou pessoa responsável pela sua própria manutenção, será comunicado às autoridades administrativas ou judiciarias, para os fins de direito. Art. 155. Em caso de grande escassez de recursos, as autoridades sanitárias procurarão auxiliar o leproso recolhido á leprosaria ou dar assistência temporária a sua família (BRASIL, 1923, p. 35).

A intervenção do Estado na profilaxia da lepra ampliava, também, as medidas intervencionistas para além do doente: "os filhos de leprosos, embora um só dos progenitores seja doente, serão mantidos em secções especiais, anexas às áreas de pessoas sãs do estabelecimento, para onde serão transportados logo depois de nascidos" (BRASIL, 1923, p. 35). No entanto, entre as décadas de 1941 e 1970, período em que o Estado "manteve" o Sanatório São Julião, a imagem retratada pela mídia impressa local sugeria que a assistência pública e a responsabilidade do Estado para com os internos e seus familiares não estavam ajustadas às suas reais necessidades. A título de exemplo, mencionem-se notícias com a produção de campanhas assistencialistas sendo mediadas pela imprensa local como forma de aproximação com a comunidade saudável, externa ao sanatório.

No dia 11 de abril de 1958, o jornal Correio do Estado publicou a notícia "Donativos ao Preventório" (DONATIVOS..., 1958), nome que se dava ao local destinado à internação das crianças sadias, filhas de pais leprosos 
internados compulsoriamente. A notícia referia-se a doações realizadas ao Preventório, atendendo a uma campanha iniciada pela Diretoria da Sociedade Campo-Grandense de Assistência aos Lázaros e Defesa contra a Lepra. Nela, encontrava-se uma lista de 14 nomes de "generosas" pessoas e instituições, com suas respectivas doações, como roupas, brinquedos, doces, comidas diversas e cobertores, entre outras. Daqueles 14 nomes listados, nove eram de mulheres, observando-se, entre eles, vários sobrenomes de famílias que compunham a elite campo-grandense, tais como Dibo, Nacer, Mandetta, Baís e outros mais. Na sequência, a notícia ressaltou outras duas ações assistencialistas, a saber: (1) a entrega de roupas confeccionadas por mulheres consideradas damas da sociedade, pelo Lions Clube e (2) a arrecadação de cobertores, no comércio, por um grupo de senhoras, "ilustres damas", como o próprio jornal enfatizou. O jornal fazia, ainda, um apelo a futuras doações, asseverando que publicaria o nome das pessoas que contribuíssem com a simpática iniciativa. Desse modo, deduz-se que era importante publicar os nomes dos benfeitores em notícias sobre a caridade social, pois tal destaque influenciaria doações futuras, além de fomentar comentários sobre as "benevolências" daquelas pessoas na cidade. Nesse sentido, os auxílios cumpriam um duplo papel: aliviar o sofrimento dos mais necessitados e atribuir status e privilégios políticos a quem os concedia, exaltando as qualidades pessoais dos mais afortunados (BOVOLENTA, 2017). À época, as ações assistencialistas apareciam em outras notícias veiculadas pela mídia impressa campo-grandense.

A notícia a que se refere a Figura 1 versa sobre uma verba, no valor de 1 milhão e 600 mil cruzeiros, para o Sanatório São Julião, proveniente do Serviço Nacional de Lepra e da possibilidade de um futuro convênio entre o Estado de Mato Grosso e o Serviço Nacional de Lepra, na importância de oito milhões, destinados ao cuidado com os leprosos do Estado. Percebe-se que a notícia veiculou a informação sobre a falta de recursos aos internos e a necessidade de envio de verbas à instituição, por parte daquele governo. A necessidade de recursos é reforçada, também, em outro jornal - Jornal do Comércio -, na data de 15 de julho de 1964 (Figura 2). 
Figura 1 - 1 milhão e 600 mil cruzeiros para o Sanatório São Julião

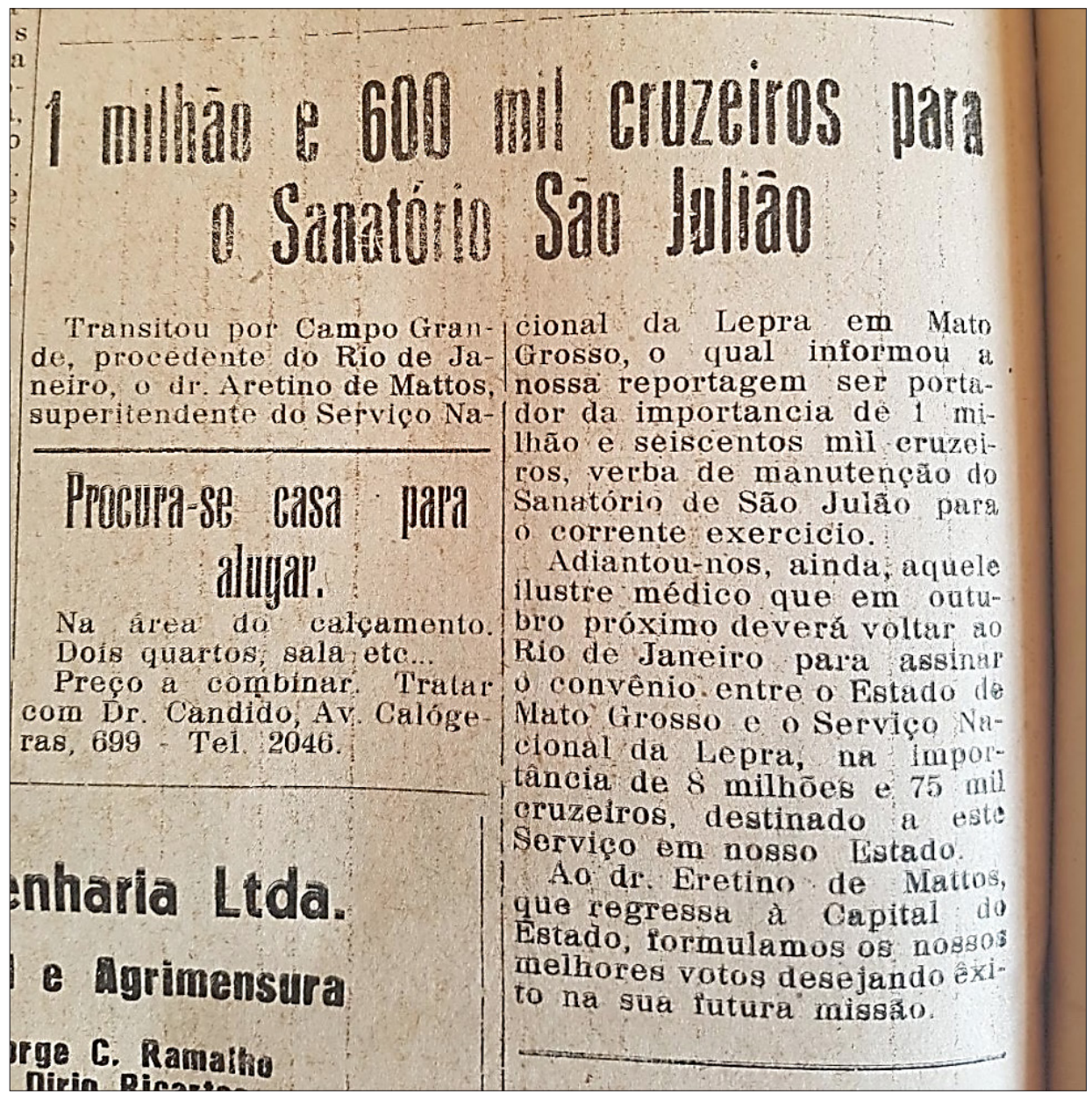

Fonte: Jornal O Matogrossense (1960). 
Figura 2 - Sanatório São Julião recebeu um milhão: encetada campanha do macarrão

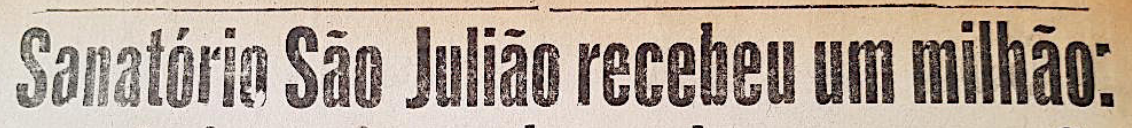

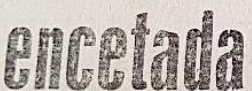

Como resultado do bin-

- go monstro, realizado sábado último na sede da

União dos Sargentos, teve lugar na tarde de anterontem, no Banco do Povo, o pagamento do prêmio maior aos dois felizes contemplados.

\section{บำ}

O prêmio, como se sabe, foi um cheque de dois milhōes e 800 mil cruzeiros, cabendo metade a cada um dos vencedores, a srta. Nair Seguni e r. Moacir Aleixo.

$\mathrm{Na}$ ocasião, foi entre gue ao Dr. Orestes Ro- cha, diretor do Sanatório São Julião a importância de um milhão de cruzeiros, que ali ficou depositada à disposição do benemérito serviço, $\mathrm{CO}^{-}$ mo a parte que lhe tocou do patriótico empreendimento.

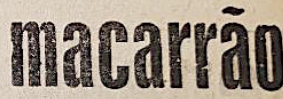

CAMPANHA

Foi lançada, naquela oportunidade, a Campanha do Quilo de Macarrão, visando melhorar a dispensa dos internados do São Julião.

\section{Instituto

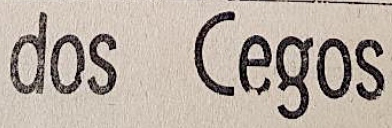

Fonte: Jornal do Comércio (1964).

O Sanatório São Julião recebeu um milhão de cruzeiros mediante recursos provenientes de um bingo realizado na cidade, em que parte da verba foi revertida àquela instituição. O bingo parece ter mobilizado uma grande parcela da sociedade, o que pode ser percebido em vários pontos da reportagem, como o fato de tê-lo intitulado de "bingo monstro". O evento foi realizado em um local amplo, a sede da União dos Sargentos, e, por ser um valor alto, o pagamento precisou ser realizado por uma instituição bancária, o Banco do Povo. Além disso, finalizada a doação, surgiu outra campanha na mesma notícia, a campanha do macarrão, voltada para a arrecadação de alimentos para favorecer a dispensa dos internos do Sanatório. Dessa forma, o que as fontes nos sugerem é que o cuidado com os isolados no São Julião aparecia a partir de práticas assistencialistas, e não como intervenções de assistência social ou à saúde daquelas pessoas. A fonte ainda nos sinaliza que, na cidade, tal prática parecia presente em outras esferas da saúde. Na mesma página, o jornal seguiu com uma próxima notícia: 
"Instituto dos Cegos prossegue campanha pró construção de sua sede". A notícia permite ver que o cenário geral referente à saúde, no Estado, não era específico ao São Julião. Campanhas em prol de doações e o incentivo a práticas assistencialistas faziam parte do contexto geral. Todavia, em relação ao São Julião, a imagem que se construía, na mídia, era da necessidade de práticas assistencialistas, na ausência de assistência social proveniente do poder público e, mais especificamente, de políticas públicas de assistência social e saúde.

No Sanatório São Julião, notavam-se, ainda, imagens "polêmicas", relatando indícios de desestabilidade administrativa, com trocas de cargo, na diretoria, por questões relacionadas à ausência de cuidados com os hansenianos, como se observa na Figura 3. A notícia apresentada nessa figura referiu-se à troca da diretoria do Sanatório São Julião, devido ao fato de seu administrador ser executor de severas e desumanas "façanhas contra os asilados", culminando com a repulsa dos internados, que teriam comemorado sua transferência com festa e canto. A notícia ressaltou que os internos ficaram livres do administrador do leprosário, Benedito Pedroso de Almeida, e o acusou de ser "executor submisso das severas [sic] e desumanas ordens do diretor Ataxerxes".

Figura 3 - Os hansenianos ficaram livres do truculento administrador do São Julião

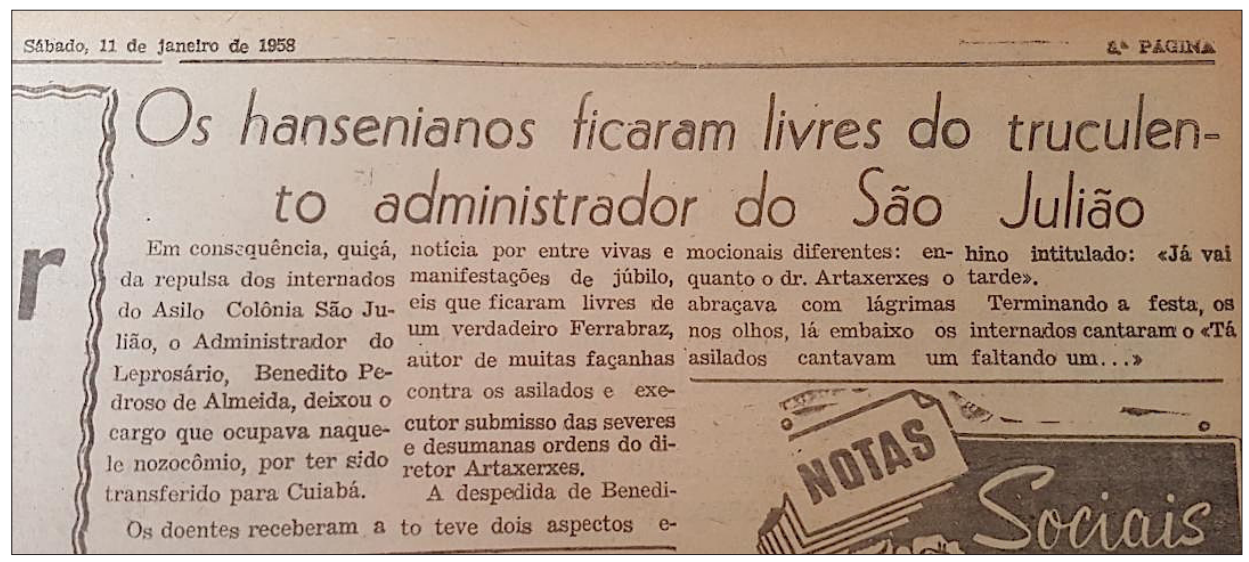

Fonte: Jornal Correio do Estado (1958). 
Tal contexto nos leva a pensar em duas situações distintas, relacionadas ao "amparo" aos leprosos: uma, no cerne da instituição, em que os internos estariam sendo vítimas de práticas severas e desumanas, e outra, no ambiente externo, por parte da sociedade, que os amparava por meio de ações assistencialistas. Nesse quadro geral, o que predominou até então foi "uma concepção de 'promoção social', ou seja, ações assistencialistas, caracterizadas pela filantropia e benemerência de entidades religiosas ou grupos organizados da sociedade civil, cujos princípios pautavam-se unicamente na necessidade de praticar a caridade e levar amor ao próximo" (BITTAR, 1999, p. 240).

Nesse sentido, a ausência de políticas públicas não sanava o problema da erradicação da lepra e do tratamento dos leprosos. Podemos considerar, desse modo, que o "amparo" destinado aos internados do Sanatório São Julião, por parte da sociedade, desempenhou um papel mais social do que terapêutico, ou seja, grande parte das doações manteve aqueles doentes alimentados, não surgindo uma prática de saúde voltada para o tratamento da doença ou do doente.

\section{CONSIDERAÇÕES FINAIS}

Este estudo objetivou apresentar a forma como o Sanatório São Julião circulou na mídia impressa campo-grandense, entre 1941 e 1970. Isso permitiu o acesso indireto ao contexto social e político da lepra e da internação compulsória no Brasil, à época. Para tanto, foi apresentada (1) uma discussão sobre as principais medidas intervencionistas para a assistência à lepra no Brasil, que confluíram com (2) o isolamento compulsório do Centro-Oeste, em Campo Grande, no Sanatório São Julião, e (3) a assistência aos internados pela imagem evocada na mídia impressa.

No contexto, foi possível analisar, mediante o exemplo da lepra, que o compromisso do Estado com a saúde se resumiu em promessas, anunciadas desde a Proclamação da República. A ideia de que a população constituía capital humano e a maneira como a medicina incorporava os novos conhecimentos clínicos e epidemiológicos levaram à elaboração de minuciosos planos de combate às enfermidades que reduziriam a vida produtiva da população - no caso da lepra, por exemplo, a exclusão dos doentes e proteção 
dos sadios. No entanto as questões relativas à saúde individual e coletiva revelaram uma "política de saúde" isolada de outros setores da sociedade, tais como educação, alimentação, habitação, entre outros. Nossas fontes nos sugerem que, na ausência de verba pública para a assistência social, a sociedade tentava suprir as carências praticando ações assistencialistas, incentivadas pela mídia impressa, que divulgava fatos correlacionados ao tema "lepra" e ao Sanatório São Julião, incentivando, assim, a ação donativa. Um exemplo dessas atitudes foram as notícias em que o cuidado pelo Estado não aparecia, em contrapartida à benevolência daquelas pessoas que doavam algo àqueles doentes internados. Desse modo, a sociedade praticava ações de caridade e filantropia, doando desde alimentos a valores altos, efetuados por "generosos" campo-grandenses, com o propósito de manter os doentes segregados e excluídos. Assim, historicamente, a política social parece ter sido o setor menos privilegiado pelo Estado. Apesar de repetidas promessas oficiais de criar condições para a melhoria do padrão de vida da população, o Estado acabava privilegiando investimentos que beneficiavam a elite econômica em detrimento da parcela mais pobre da sociedade.

Por fim, é preciso reconhecer certas limitações metodológicas do nosso estudo, as quais entendemos se relacionarem, e. g., a uma amostra pequena de recortes de jornais, limitada ao Estado de Mato Grosso e a fontes restritas a um único arquivo, o ARCA. Portanto o presente trabalho não tem a pretensão de responder a todos os questionamentos suscitados sobre o Sanatório São Julião, a partir das imagens evocadas pela mídia impressa. As questões aqui geradas resumem-se a um ponto de partida para futuras reflexões sobre os desdobramentos entre a lepra e a hanseníase e o Sanatório São Julião. Estudos futuros poderão expandir nossas fontes, além de identificar e analisar outros fenômenos que desvelem histórias sobre a hanseníase no país. Entretanto as limitações não parecem prejudicar as conclusões que ora se apresentam. Olhar para o passado, por meio da história da internação compulsória em Campo Grande, permite-nos - e nos ajuda - entender possíveis atualizações que tais fenômenos produzem no presente, quando nos deparamos com o questionamento do motivo pelo qual a hanseníase se constitui em um problema atual de saúde pública e por que ainda não foi erradicada no país. 
O Sanatório São Julião na mídia impressa campo-grandense (1941-1970): um estudo historiográfico

\section{REFERÊNCIAS}

ALVES, F. N. O ensino da história por meio dos jornais antigos: as imagens acerca dos atores político-partidários à época imperial. História, Rio Grande, RS, v. 3, n. 1, p. 19-36, 2012.

BARROS FILHO, C. Ética na comunicação: da informação ao receptor. São Paulo: Moderna, 2005.

BATISTA, R. L. L.; MACHADO, M. N. M.; GERKEN, C. H. S. A construção discursiva da autoridade e do saber salesiano no jornal Diário do Comércio de São João del-Rei. Memorandum, Belo Horizonte, MG, v. 28, p. 145-70, abr. 2015.

BERTOLLI FILHO, C. História da saúde pública no Brasil. 4. ed. São Paulo: Ática, 2004.

BITTAR, M. Da promoção à assistência social: Campo Grande na luta pela cidadania. In: CUNHA, F. A. Campo Grande 100 anos de construção. Campo Grande: Matriz, 1999. p. 237-53.

BOVOLENTA, G. A. A atenção aos pobres: apontamentos históricos sobre a assistência e proteção social no Brasil. História e Cultura, Franca, SP, v. 6, n. 2, p. 9-34, ago./nov. 2017.

BRASIL. Decreto de n. 16.300, de 31 de dezembro de 1923. Aprova o regulamento do Departamento Nacional de Saúde Pública. Diário Oficial da União, Rio de Janeiro, 1923.

CAMPESTRINI, H.; GUIMARÃES, A. História de Mato Grosso do Sul. Campo Grande: Tribunal de Justiça de Mato Grosso do Sul, 1991. Edição histórica.

CANIATO, L. A história do São Julião de 1941 a 2013. Campo Grande, MS: [s.n.], 2013.

CARA, B. S.; DELMONDES, G. F. S.; BATISTA, R. L. L.; MIRANDA, R. L. Universidade e psicologia no Diário da Serra: alguns apontamentos para uma história da Psicologia em Campo Grande. In: JACÓ-VILELA, A. M.; DEGANI-CARNEIRO, F.; ARAÚJO, J. H. Q. (Org.). Clio-psyché - saberes psi: novos sujeitos, outras histórias. Curitiba: Juruá, 2018. p. 83-93.

CASTRO, E. A. O leprosário São Roque e a modernidade: uma abordagem da hanseníase na perspectiva da relação espaço-tempo. Revista $R A^{\prime} E G A$, Curitiba, n. 10, p. 9-32, 2005. 
CASTRO SANTOS, L. A.; FARIA, L.; MENEZES, R. F. Contrapontos da história da hanseníase no Brasil: cenários de estigma e confinamento. Revista Brasileira de Estudos de População, São Paulo, v. 25, n. 1, p. 167-90, jan./jun. 2008.

COSTA, D. F. A. C. Entre idéias e ações: lepra, medicina e políticas públicas de saúde no Brasil (1894-1934). 2007. 410 f. Tese (Doutorado em História)- Universidade Federal Fluminense, Niterói, RJ, 2007.

COSTA, C. Evolução urbana. In: CUNHA, F. A. M. (Coord.). Campo Grande 100 anos de construção. Campo Grande, MS: Matriz, 1999. p. 71-82.

CUNHA, V. S. Isolados 'como nós' ou isolados 'entre nós'?: a polêmica na Academia Nacional de Medicina sobre o isolamento compulsório dos doentes de lepra. História, Ciências, Saúde-Manguinhos, Rio de Janeiro, v. 17, n. 4, p. 939-54, out./ dez. 2010.

DONATIVOS ao Preventório. Jornal Correio do Estado, Campo Grande, MS, 1958.

ESPÍRITO SANTO, T. B. E.; OGUISSO, T.; FONSECA, R. M. G. S. A profissionalização da enfermagem brasileira na mídia escrita no final do século XIX: uma análise de gênero. Revista Latino-Americana de Enfermagem, Ribeirão Preto, SP, v. 19, n. 5, p. 1-7, set./out. 2011.

GALVÃO, O. C. História da medicina de Campo Grande. In: I: CUNHA, F. A. M. (Coord.). Campo Grande 100 anos de construção. Campo Grande, MS: Matriz, 1999. p. 255-72.

HOHLFELDT, A. Os estudos sobre a hipótese do agendamento. Revista Famecos, Porto Alegre, RS, v. 4, n. 7, p. 42-51, nov. 1997.

LAPUENTE, R. S. O jornal impresso como fonte de pesquisa: delineamentos metodológicos. In: ENCONTRO NACIONAL DA HISTÓRIA DA MÍDIA, 10., 2015, Porto Alegre, RS. Anais [...]. Porto Alegre, RS: Pontifícia Universidade Católica do Rio Grande do Sul, 2015.

LEANDRO, J. A. A hanseníase no Maranhão na década de 1930: rumo à Colônia do Bonfim. História, Ciências, Saúde-Manguinhos, Rio de Janeiro, v. 16, n. 2, p. 433-47, abr./jun. 2009.

LIMA, E. D.; OLIVEIRA, P. F. Discurso e identidade: a construção discursiva do 
O Sanatório São Julião na mídia impressa campo-grandense (1941-1970): um estudo historiográfico

Nordeste na mídia paraibana. Psicologia Política, São Paulo, v. 15, n. 34, p. 497514, set./dez. 2015.

LE GOFF, J. História e memória. Campinas, SP: Unicamp, 1990.

MACIEL, R. L. "Em proveito dos sãos perde o lázaro a liberdade": uma história das políticas públicas de combate à lepra no Brasil (1941-1962). 2007. 380 f. Tese (Doutorado em História)- Universidade Federal Fluminense, Niterói, RJ, 2007.

NASCIMENTO, H. B. A lepra em Mato Grosso: caminhos da segregação social e do isolamento hospitalar (1924-1941). 2001. 178 f. Dissertação (Mestrado em História)- Universidade Federal de Mato Grosso, Cuiabá, 2001.

OPROMOLLA, P. A.; LAURENTI, R. Controle da hanseníase no Estado de São Paulo: análise histórica. Revista de Saúde Pública, São Paulo, v. 45, n. 1, p. 195-203, 2011.

OS HANSENIANOS ficaram livres do truculento administrador do São Julião. Jornal Correio do Estado, Campo Grande, 1958.

SÁ, C. P. Sobre o campo de estudo da memória social: uma perspectiva psicossocial. Psicologia: Reflexão e Crítica, Porto Alegre, v. 20, n. 2, p. 290-95, 2007.

SANTOS, V. S. M. Filantropia, poder público e combate à lepra. História, Ciências, Saúde-Manguinhos, Rio de Janeiro, v. 18, supl. 1, p. 253-74, dez. 2011.

SANTOS, V. S. M. Pesquisa documental sobre a história da hanseníase no Brasil. História, Ciências, Saúde-Manguinhos, Rio de Janeiro, v. 10, supl. 1, p. 415-26, 2003.

SANATÓRIO São Julião recebeu um milhão: encetada campanha do macarrão. Jornal do Comércio, Campo Grande, 1964.

SILVA, L. F. A construção da lepra em Goiás: contágio e isolamento (1890-1943). Fronteiras: Journal of Social, Technological and Environmental Science, Anápolis, GO, v. 4, n. 1, p. 38-56, jan./jul. 2015. Disponível em: http://revistas.unievangelica. edu.br/index.php/fronteiras/

1 MILHÃO e 600 mil cruzeiros para o Sanatório São Julião. Jornal O mato-grossense, Campo Grande, 1960. 
VILENA, K. C. G. História de práticas de saúde no Sanatório São Julião (1941-1986). 2018. 156 p. Dissertação (Mestrado em Psicologia) - Universidade Católica Dom Bosco, Campo Grande, MS, 2018.

WOLF, M. Teorias da comunicação de massa. 2. ed. São Paulo: Martins Fontes, 2005. 